Article

\title{
Study of the Surface and Dimensional Quality of the AlSi10Mg Thin-Wall Components Manufactured by Selective Laser Melting
}

\author{
Muhammad Waqas ${ }^{1}$, Dingyong He ${ }^{1}\left(\mathbb{D}\right.$, Hassan Elahi $^{2, *} \mathbb{D}$, Saleem Riaz ${ }^{3} \mathbb{D}$, Marco Eugeni $^{2}(\mathbb{D}$ \\ and Paolo Gaudenzi ${ }^{2}$ \\ 1 Faculty of Materials and Manufacturing, Beijing University of Technology, No.100, Ping Le Yuan, \\ Beijing 100124, China; waqasm082@yahoo.com (M.W.); dyhe@bjut.edu.cn (D.H.) \\ 2 Department of Mechanical and Aerospace Engineering, Sapienza University of Rome, 00185 Roma, Italy; \\ marco.eugeni@uniroma1.it (M.E.); paolo.gaudenzi@uniroma1.it (P.G.) \\ 3 School of Automation, Northwestern Polytechnical University, Xi'an 170072, China; \\ saleemriaznwpu@mail.nwpu.edu.cn \\ * Correspondence: hassan.elahi@uniroma1.it
}

check for updates

Citation: Waqas, M.; He, D.; Elahi, H.; Riaz, S.; Eugeni, M.; Gaudenzi, P. Study of the Surface and Dimensional Quality of the AlSi10Mg Thin-Wall Components Manufactured by Selective Laser Melting. J. Compos. Sci. 2021, 5, 126. https://doi.org/ $10.3390 /$ jcs5050126

Academic Editor: Nikolaos

G. Semaltianos

Received: 11 April 2021

Accepted: 7 May 2021

Published: 9 May 2021

Publisher's Note: MDPI stays neutral with regard to jurisdictional claims in published maps and institutional affiliations.

Copyright: (c) 2021 by the authors. Licensee MDPI, Basel, Switzerland. This article is an open access article distributed under the terms and conditions of the Creative Commons Attribution (CC BY) license (https:// creativecommons.org/licenses/by/ $4.0 /)$.

\begin{abstract}
Additive manufacturing (AM), a 3D printing technique that manufactures components by sequential addition of powder, has massively reshaped the manufacturing and engineering sectors from batch production to manufacturing customized, innovative, state-of-the-art, and sustainable products. Additive manufacturing of aluminum alloys by selective laser melting (SLM) is one of the latest research trends in this field due to the fact of its advantages and vast applications in manufacturing industries such as automobiles and aerospace. This paper investigated the surface and dimensional quality of SLM-built AlSi10Mg parts using a response surface method (RSM) and found the influence of the wall thickness and process parameters (i.e., laser power, scanning speed, hatch distance) on the pieces. Thin-walled test specimens of AlSi10Mg alloy were manufactured with different combinations of process parameters at three wall thicknesses: $1.0 \mathrm{~mm}, 2.0 \mathrm{~mm}$, and $3.0 \mathrm{~mm}$. The Minitab DOE module was used to create 27 different configurations of wall thickness and process parameters. The samples' surface roughness and dimensional accuracy were investigated, and the findings were evaluated using the ANOVA technique. The regression model and the ANOVA technique showed high precision and had a particular reference value for practical engineering applications.
\end{abstract}

Keywords: selective laser melting; AlSi10Mg; surface roughness; dimensional accuracy

\section{Introduction}

Additive manufacturing (AM) techniques, along with newly developed alloys and conventional manufacturing processes, possess the ability to transform the method of production of industrial products. AM methods are often mentioned as layered manufacturing, owing to the nature of the procedure which involves layer-by-layer fabrication of a part while using CAD data from a computer [1-3]. AM is a generally used term in the manufacturing industry, but autofab (auto fabrication), freeform manufacturing, powder metallurgy, stereo lithography, layer-based manufacturing, and 3D printing are also commonly used terminologies while referring to additive manufacturing [2]. In the late 1980s, manufacturing industries started using additive manufacturing techniques to produce prototypes of their products for the purpose of assessing the difficulties associated with their geometry, design, and form along with their usefulness. At the end of 1990s and in the early 2000s, due to the great improvements in the reproducibility and reliability of the method, and while referring to metallic materials, owing to the employment of high-energy density sources able to consolidate these metallic materials, application of AM techniques and 3D 
printing began for the production of final products [2,4-6]. Nowadays, additive manufacturing has replaced some traditional production processes, for instance, casting and forging, especially in some specific manufacturing industries, e.g., the automotive and aerospace industries. The main factors for the adoption of AM in these industries are its advantages over conventional manufacturing process such as the high degree of freedom in design and complexity of geometry, the ability to manufacture freeform surfaces, amalgamation of many components into one-part, minimal requirement of work tools, and the ability to customize production [4,7-9]. Over the last two decades, AM has been transformed from rapid prototyping-oriented $3 \mathrm{D}$ printers to advanced production systems having the ability to produce fully functional components of different materials with minimal involvement of tooling. So far, the focus of research in 3D printing has been the production of parts using polymer materials, but the invention of new AM techniques, including selective laser sintering/melting, laser engineered net shaping, and electron beam melting, made it possible to manufacture metallic, ceramic, and composite parts. The automobile, aerospace, military production, and biomedical industries are leading sectors utilizing additively manufactured parts [4,9-11]. The employment of AM techniques has granted designers high freedom of design and enabled manufacturing industries to produce topologically optimized components with better strength-to-weight ratios, an essential characteristic in both automobile and aerospace designs in order to produce light-weight products. AM has enormously revolutionized the biomedical industry with customized production of prosthetic parts, dental implants, hearing aids, and orthopedic parts to suit the unique needs of an individual's physiology. AM has rapidly revamped the manufacturing process within the last ten years and produced practically functional components, making these techniques commercially popular $[6,9,12]$.

Surface roughness is one of the most important factors when evaluating the surface quality of components, and roughness has a major impact on the mechanical properties that affect the service life of components. Therefore, the role of surface roughness in the SLM parts has been investigated by many researchers. To discover the related factors influencing surface roughness, various scientific studies have been carried out.

The effects of laser power and scan speed on the surface roughness of the printed aluminum alloy samples were investigated by Dad bakhsh et al. [13]. Calignano et al. [14] concluded that with direct metal laser sintering (DMLS), the scanning speed has a significant impact on the surface roughness. Leary [15] conducted a series of surface roughness optimizations for Ti6Al4V specimens. The effect of input LEDs on the surface roughness of aluminum alloy specimens with DMLS was studied by Mohammadi and Asgari [16], but it was confined to the construction plane. Wang et al. investigated the surface roughness of SLM-built AlSi10Mg parts and established that the surface roughness first decreases noticeably and then rises gradually with the increase in laser energy density [17]. The SLM process parameters' effect on surface roughness was studied by Tian et al., and it was observed that surface roughness increased with small hatch distances that led to the adhesion of particles on the surface. They also found that good surface quality can be achieved by better scan strategies [18]. Rakesh et al. compared the effects of argon- and nitrogen-built environments for SLM of AlSi10Mg and concluded that samples built in a nitrogen atmosphere reported smoother surfaces and better mechanical properties [19].

Han et al. [20] focused on the various process parameters that influenced dimensional accuracy and recognized that a high scan speed, resulting in high densification, can help to improve dimensional accuracy. Majeed et al. [21] studied the surface and dimensional quality of SLM-built AlSi10Mg parts and defined a set of optimal process parameters. Maamoun et al. investigated the effects of the SLM process parameters on the dimensional accuracy of the AlSi10Mg parts. The results reported a dimensional tolerance variation from an oversize of $0.15-0.195 \mathrm{~mm}$ [22]. Sing et al. stated that the geometrical precision of the lattice structures can be enhanced by cautious variations of the process parameters. The research concluded that laser power, as compared to layer thickness and scan speed, greatly influences the dimensional accuracy of lattice structures built by SLM [23]. The 
dimensional quality of SLM- and DMLS-built internally cooled cutting tools was studied by Ghani et al. They concluded that, with respect to dimensional accuracy, the DMLS method performed better than the SLM method [24]. Fateri et al. investigated the SLM of glass, finding that both high- and low-energy intensities led to poor dimensional quality causing bulging and poor bonding, respectively. They showed that 100\%-dimensional accuracy is attainable by selection of the optimal process parameters [25]. Wang et al. studied the SLS process parameters' effect on dimensional accuracy and concluded that the accuracy of SLS-built parts can be improved with a higher laser power, lower scanning speed, and maximum permissible temperature of working atmosphere [26].

It is evident from the literature that there are a number of SLM process parameters that can be controlled and varied so as to obtain the desirable surface and dimensional quality of the parts. This study aimed to investigate the effect on the surface and dimensional quality of SLM-built test specimens of various combinations of laser power, scan speed, hatch distance, and wall thicknesses.

\section{Experimental Method and Procedure}

\subsection{Equipment and Material}

To manufacture the sample under study, a gas-atomized AlSi10Mg powder material was used, which is commonly used for aluminum moldings. The powder was supplied by the PAC Corporation (USA). An SLM 280HL machine of SLM solutions was employed to produce the sample. The aluminum substrate was heated to $150{ }^{\circ} \mathrm{C}$ to avoid the thermal stresses. Prior to the start of fabrication, the AlSi10Mg powder was dried out by exposing it to a temperature of $70{ }^{\circ} \mathrm{C}$ in a drying oven for $4 \mathrm{~h}$. The sieving of the powder was performed in order to filter out the particles between the size of $18-58 \mathrm{~mm}$ for onward production. The machine used, an SLM 280HL, was supplied with the maximum scan speed of $10 \mathrm{~m} / \mathrm{s}$ and two fiber lasers each with laser power of 400 watts. Build platform used to produce samples consisted of a $280 \mathrm{~mm} \times 280 \mathrm{~mm}$ square plate. The selection of suitable process parameters is very significant for accomplishing the best results from the SLM technique. The scan speed, hatch distance, and laser power are vital parameters in the SLM process. The almost eutectic structure of AlSi10Mg in the Al-Si phase diagram and a melting temperature of $570{ }^{\circ} \mathrm{C}$ make it one of the most suitable and widely used alloys in casting. This alloy, due to the fact of its hardness and good strength, is used for thin wall and intricate geometry components prone to high loads such as in automotive and aerospace productions $[27,28]$. The chemical composition of AlSi10Mg is given below in Table 1.

Table 1. Composition of AlSi10Mg alloy powder as per DIN EN 1706.

\begin{tabular}{ccccccccc}
\hline ELEMENT & $\mathbf{S i}$ & $\mathbf{F e}$ & $\mathbf{C u}$ & $\mathbf{M n}$ & $\mathbf{M g}$ & $\mathbf{Z n}$ & $\mathbf{T i}$ & $\mathbf{A l}$ \\
\hline Weight $\%$ & $9-11$ & $\leq 0.55$ & $\leq 0.05$ & $\leq 0.45$ & $0.2-0.45$ & $\leq 0.1$ & $\leq 0.15$ & Balance \\
\hline
\end{tabular}

\subsection{Powder Characterization}

The morphology of the AlSi10Mg powder particles was examined on a scanning electron microscopy (SEM) and images were taken by a Tescan VEGA 3 LMU Scanning Electron Microscope system as shown in Figure 1. A laser particle analyzer (Beckman Coulter LS 13,320) was used to measure the size of powder particles. The powder particles size varied from an average diameter of 25-65 $\mu \mathrm{m}$; however, some particles also had diameters smaller and larger than the abovementioned range, having different spherical and elliptical forms. The density of the loose powder was $2.68 \mathrm{gm} / \mathrm{cm}^{3}$ as per the data sheet provided by PAC Corporation. 
(a)

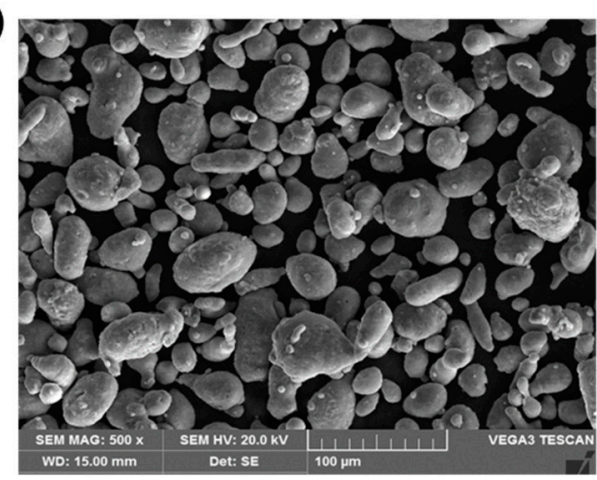

(b)

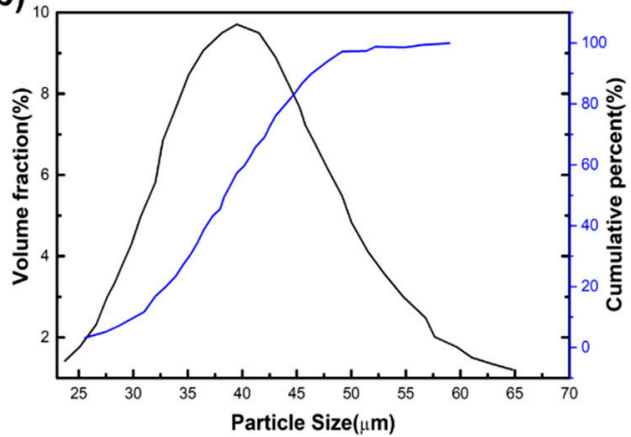

Figure 1. Morphology of AlSi10Mg; (a) powder particles, and (b) the powder size distribution.

\subsection{Response Surface Methodology in Combination with Design of Experiment (DOE)}

The response surface method (RSM) is a group of procedures that includes (1) outlining a group of experimentations in order to obtain trustworthy and satisfactory measurement of the response under study, (2) defining a set of the optimum process parameters that lead to the attainment of the desired value of response, and (3) explaining the influence of selected process parameters upon the response with the help of 2D and 3D plots and response surfaces. The response surface methods are categorized into three different kinds of design of experiments (DOE) techniques: (1) central composite design (CCD) was developed by Box and Wilson in 1951 and is capable of designing experimental plans up to five levels; (2) Box-Behnken design (BBD) proposed by Box and Behnken in 1960, which has the capacity to outline experimental plans up to three levels; (3) EIMSE-optimal designs presented by Allen et al. in 2003, founded on supposed "expected integrated mean squared error optimal" $[29,30]$.

The optimization of parameters in the SLM process can be beneficial to enhance the surface and dimensional quality of fabricated parts [14,31-33]. This research aimed to undertake a comprehensive understanding of the relationship between different sets of process parameters and the surface and dimensional quality of SLM-built AlSi10Mg parts. The study, by use of optimization techniques, also tried to outline the optimized process parameters to attain better surface and dimensional quality. The main objectives of this study are as given below:

- Investigation of SLM process parameters' influence upon the surface and dimensional quality of AlSi10Mg specimens;

- To study the impact of variations of wall thickness and process parameters on surface roughness and the dimensional accuracy of the specimens;

- To determine the effect of post-processing techniques (i.e., sand blasting and polishing) on the surface and dimensional quality of the specimens;

- By using optimization techniques, to define a set of optimal process parameters against surface roughness and dimensional accuracy.

\section{DOE by Using Minitab 17}

There are many statistical software tools available for DOE and optimization purposes such as Design Expert, Statistica, Minitab, Design-Ease. Minitab 17 was used in this study for experiment planning, regression analysis, and optimization of the SLM process against surface roughness and dimensional accuracy.

This study proposes a BBD-based optimization approach. This approach, by outlining the least possible runs of experiment, suggests a set of optimum process parameters (i.e., laser power, scan speed, hatch distance) of the selective laser melting process. Response surface methods are normally applied in scenarios when the importance of some factors (process parameters) have already been established as a result of previous experimentation [29]. The DOE starts by defining the factors (in this case. the SLM process parameters) 
and their levels (highs and lows). In continuation of previous research work done [34,35], three levels of four parameters (i.e., wall thickness, laser power, scan speed, and hatch spacing) were selected. The three levels of parameters employed in this study are given below in Table 2.

Table 2. Process parameters and their levels for DOE.

\begin{tabular}{ccccc}
\hline \multirow{2}{*}{ Parameters } & Unit & $\mathbf{- 1}$ & Level \\
\cline { 3 - 5 } & & 1.0 & $\mathbf{0}$ & $\mathbf{1}$ \\
\hline Wall Thickness & $\mathrm{mm}$ & 320 & 2.0 & 3.0 \\
Laser Power & Watt & 730 & 350 & 380 \\
Scan Speed & $\mathrm{mm} / \mathrm{s}$ & 80 & 900 & 1070 \\
Hatch Distance & $\mu \mathrm{m}$ & 105 & 130 \\
\hline
\end{tabular}

The powder layer thickness was kept constant at $30 \mu \mathrm{m}$. The experimental plan was further tested, and surface plots were produced to describe the tendency of attainable surface-roughness and dimensional accuracy against different sets of process parameters. Eventually, this is beneficial in investigating the process parameters' effect upon the subsequent responses. Moreover, it also makes us capable of defining a set of optimal process parameters with respect to dimensional accuracy and surface roughness of SLM-built AlSi10Mg specimens. The Box-Behnken design-based experimental plan generated by Minitab 17 is given below in Table 3.

Table 3. Four-factor three-level Box-Behnken DOE.

\begin{tabular}{ccccc}
\hline Run Order & $\begin{array}{c}\text { Wall Thickness } \\
(\mathbf{m m})\end{array}$ & $\begin{array}{c}\text { Laser Power } \\
(\text { Watt })\end{array}$ & $\begin{array}{c}\text { Scan Speed } \\
(\mathbf{m m} / \mathbf{s})\end{array}$ & $\begin{array}{c}\text { Hatch Distance } \\
(\boldsymbol{\mu} \mathbf{m})\end{array}$ \\
\hline 1 & 1 & 320 & 900 & 105 \\
2 & 3 & 320 & 900 & 105 \\
3 & 1 & 380 & 900 & 105 \\
4 & 3 & 380 & 900 & 105 \\
5 & 2 & 350 & 730 & 80 \\
6 & 2 & 350 & 1070 & 80 \\
7 & 2 & 350 & 730 & 130 \\
8 & 2 & 350 & 1070 & 130 \\
9 & 1 & 350 & 900 & 80 \\
10 & 3 & 350 & 900 & 80 \\
11 & 1 & 350 & 900 & 130 \\
12 & 3 & 350 & 730 & 130 \\
13 & 2 & 320 & 730 & 105 \\
14 & 2 & 380 & 1070 & 105 \\
15 & 2 & 320 & 1070 & 105 \\
16 & 2 & 730 & 105 \\
17 & 380 & 730 & 105 \\
18 & 1 & 1070 & 105 \\
19 & 3 & 350 & 1070 & 105 \\
20 & 1 & 900 & 80 \\
21 & 3 & 350 & 900 & 80 \\
22 & 2 & 350 & 900 & 130 \\
23 & 2 & 350 & 900 & 130 \\
24 & 2 & 380 & 900 & 105 \\
25 & 2 & 320 & & 105 \\
26 & 2 & 380 & 350 & \\
27 & 2 & 350 & & \\
\hline
\end{tabular}

The DOE plan consisted of 27 experimental runs with different combinations of process parameters so as to minimize the experimental cost and achieve optimization. The DOE plan does not combine all the lows or highs of all the parameters in a single run 
so as to avoid extreme conditions during experimentation. Moreover, the experimental plan contains three center points, i.e., points where the middle values $(0,0,0,0)$ of all the parameters are chosen in a single run (Run 25,26,27). In this case, the middle values of wall thickness, laser power, scan speed, and hatch distance are $2 \mathrm{~mm}, 350$ watts, $900 \mathrm{~mm} / \mathrm{s}$, and $105 \mu \mathrm{m}$, respectively. A center point is repeated twice to ensure the repeatability and dispersion of the experimental design.

\section{Experimental Results and Analysis}

\subsection{Experimental Approach}

In this study, two sets out of a total of $54(27 \times 02)$ test specimens of AlSi10Mg were manufactured using the selective laser melting technique. As mentioned earlier, BoxBehnken design, which is an RSM design, was applied to outline the experimental plan. First, a three-dimensional CAD model of the samples was prepared. The CAD model was fed into the SLM machine and the manufacturing was performed. The length (L) and height $(\mathrm{H})$ of the samples were kept constant at $55 \mathrm{~mm}$ and $12 \mathrm{~mm}$, respectively, and there were three variations in wall thickness, i.e., $1.0 \mathrm{~mm}, 2.0 \mathrm{~mm}$, and $3.0 \mathrm{~mm}$, against different combinations of process parameters (i.e., laser power, scan speed, hatch distance) to make 27 combinations as designed by the DOE technique. The wall thicknesses and process parameters were varied systematically to study their effects on the surface and dimensional quality of the built specimens. The specimens' dimensions and built orientation were given in Figure 2. The wall thickness $(\mathrm{T})$ and length $(\mathrm{L})$ of the samples were built in the horizontal direction (i.e., $x, y$-plane), while the height was built in the vertical direction, i.e., on the $z$-axis. The samples were allowed to cool down at room temperature to relieve residual stresses. Then, samples were subjected to sand blasting at a pressure of $0.3 \mathrm{MPa}$ for $4 \mathrm{~min}$. The wire cutting process was applied to separate specimens from the built platform and to obtain the final shape required for further tensile and hardness testing. The length and height of the samples after wire cutting were $53 \mathrm{~mm}$ and $10 \mathrm{~mm}$, respectively. The dimensions of the final specimen after the wire cutting process are given in Figure 3 . The overall flow of the manufacturing process is given in Figure 4.
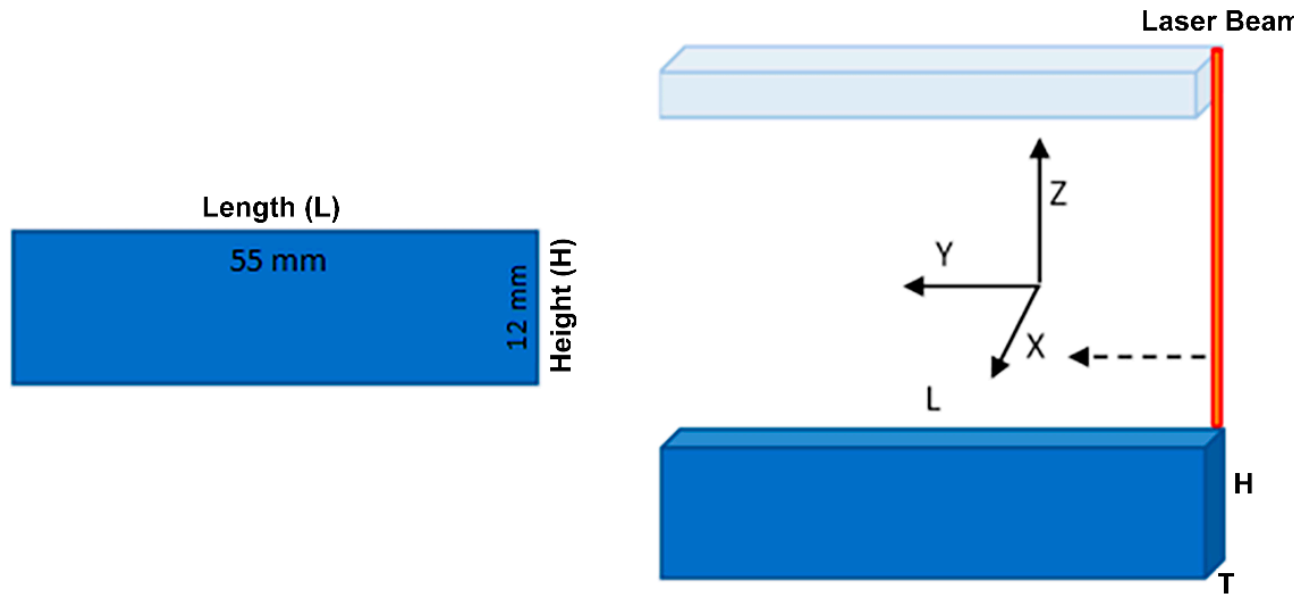

Figure 2. Samples dimensions and built-up scheme. 


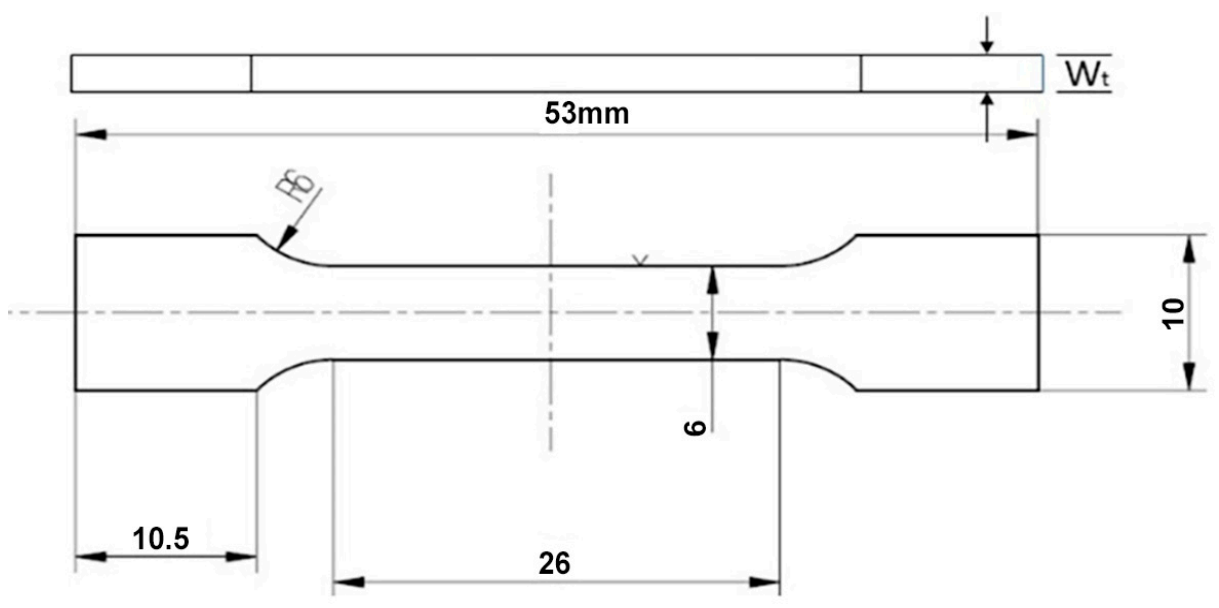

Figure 3. Dimensions of the sample after wire cutting.

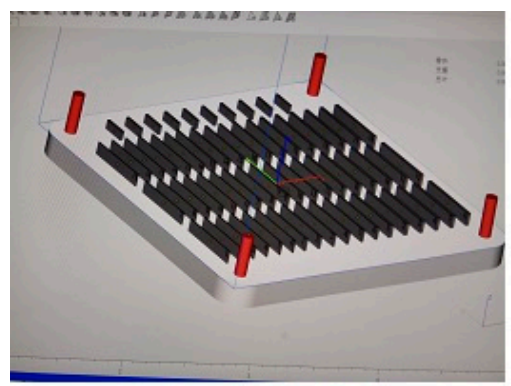

3D CAD Model

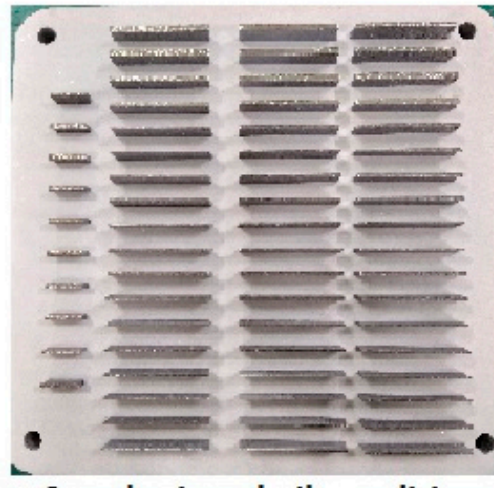

Samples in as-built condition

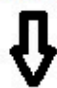

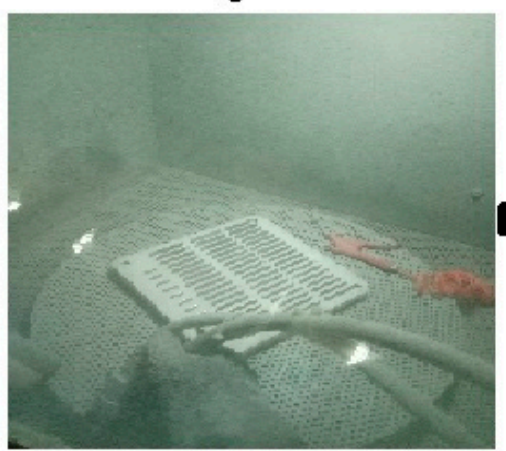

Sand Blasting

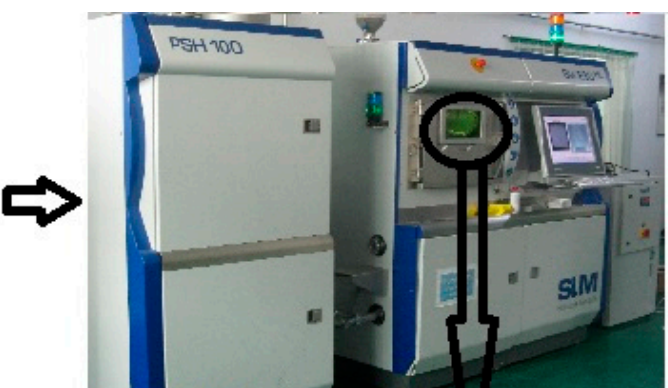

SLM Machine is fed with CAD model

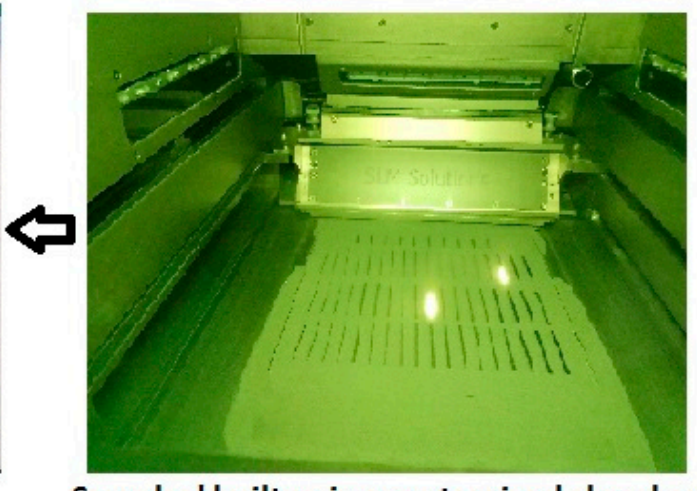

Samples' builtup in gas atomized chamber

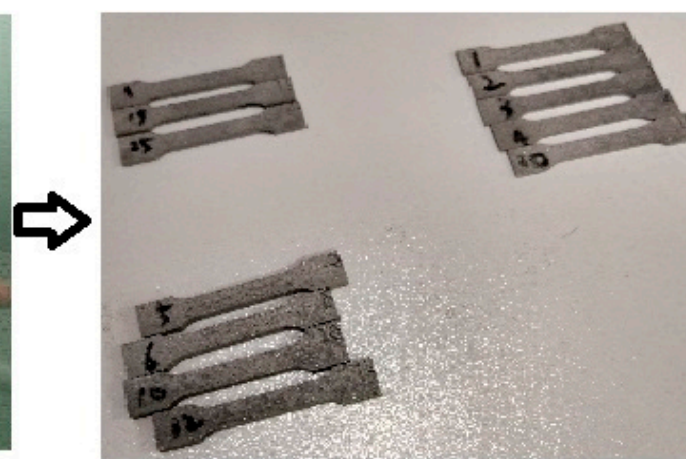

Samples after wire cutting

Figure 4. Overall flow of the manufacturing process. 


\subsection{Surface Roughness of as-Built Samples}

The purpose of experimentation, as stated earlier, was to optimize the process parameters of the SLM process to improve the surface quality of AlSi10Mg parts. The samples' surface roughness was recorded using the contact method. A profilometer was used to take a reading of the sample's SR. The profilometer records an average SR Ra in $\mu \mathrm{m}$ by moving its stylus over the surface of a sample in a straight line. The roughness reading was noted on eight different points along the longitudinal axis of each sample and the average of the values was taken. The roughness of samples in as-built condition against each experimental run is given below in Table 4 .

Table 4. Average SR values in As-built condition.

\begin{tabular}{cccccc}
\hline Run Order & WT $(\mathbf{m m})$ & LP $(\mathbf{W})$ & SS $(\mathbf{m m} / \mathbf{s})$ & HD $(\boldsymbol{\mu m})$ & SR $(\boldsymbol{\mu m})$ \\
\hline 1 & 1 & 320 & 900 & 105 & 11.575 \\
2 & 3 & 320 & 900 & 105 & 8.985 \\
3 & 1 & 380 & 900 & 105 & 8.873 \\
4 & 3 & 380 & 900 & 105 & 12.210 \\
5 & 2 & 350 & 730 & 80 & 12.156 \\
6 & 2 & 350 & 1070 & 80 & 10.391 \\
7 & 2 & 350 & 730 & 130 & 13.111 \\
8 & 2 & 350 & 1070 & 130 & 9.563 \\
9 & 1 & 350 & 900 & 80 & 11.012 \\
10 & 3 & 350 & 900 & 80 & 11.610 \\
11 & 1 & 350 & 900 & 130 & 13.816 \\
12 & 3 & 350 & 900 & 130 & 10.146 \\
13 & 2 & 320 & 730 & 105 & 9.538 \\
14 & 2 & 380 & 730 & 105 & 9.993 \\
15 & 2 & 320 & 1070 & 105 & 10.159 \\
16 & 2 & 380 & 1070 & 105 & 10.477 \\
17 & 1 & 350 & 730 & 105 & 10.240 \\
18 & 3 & 350 & 730 & 105 & 12.682 \\
19 & 1 & 350 & 1070 & 105 & 10.108 \\
20 & 3 & 350 & 1070 & 105 & 9.587 \\
21 & 2 & 320 & 900 & 80 & 11.086 \\
22 & 2 & 380 & 900 & 80 & 10.945 \\
23 & 2 & 320 & 900 & 130 & 11.818 \\
24 & 2 & 380 & 900 & 130 & 9.182 \\
25 & 2 & 350 & 900 & 105 & 9.727 \\
26 & 2 & 350 & 900 & 105 & 10.869 \\
27 & 350 & 900 & 105 & 10.253 \\
\hline
\end{tabular}

The results indicate that a minimum value of surface roughness, i.e., $\mathrm{Ra}=8.873 \mu \mathrm{m}$ was recorded in the specimen of Run Order \#3 having a wall thickness of $1.0 \mathrm{~mm}$, laser power of 380 watts, scan speed of $900 \mathrm{~mm} / \mathrm{s}$, and hatch distance of $105 \mu \mathrm{m}$. The maximum value of SR (i.e., $13.816 \mu \mathrm{m}$ ) was seen in the specimen with run order \#11. The corresponding values of wall thickness, laser power, scan speed, and hatch distance were $1.0 \mathrm{~mm}, 350$ watts, $900 \mathrm{~mm} / \mathrm{s}$, and $130 \mu \mathrm{m}$, respectively.

\subsubsection{Surface Roughness of Sand-Blasted Samples}

One of the objectives of the experiment was to study the effects of one of the postprocessing techniques (i.e., sand blasting) on the surface quality of the test specimens. As stated previously, the specimens were exposed to sand blasting at a pressure of $0.3 \mathrm{MPa}$ for $4 \mathrm{~min}$. A profilometer was used to measure the SR of specimens. The profilometer records average SR Ra in $\mu \mathrm{m}$ by moving its stylus over the surface of a sample in a straight line. The roughness reading was noted on eight different points along the longitudinal axis of each sample and the average of the values was taken. The average SR of samples after sand blasting against each experimental run is given below in Table 5 . 
Table 5. Average SR values after sand blasting.

\begin{tabular}{cccccc}
\hline Run Order & WT $(\mathbf{m m})$ & LP $(\mathbf{W})$ & SS $(\mathbf{m m} / \mathbf{s})$ & HD $(\boldsymbol{\mu m})$ & SR $(\boldsymbol{\mu m})$ \\
\hline 1 & 1 & 320 & 900 & 105 & 6.355 \\
2 & 3 & 320 & 900 & 105 & 6.590 \\
3 & 1 & 380 & 900 & 105 & 6.748 \\
4 & 3 & 380 & 900 & 105 & 8.040 \\
5 & 2 & 350 & 730 & 80 & 5.557 \\
6 & 2 & 350 & 1070 & 80 & 5.337 \\
7 & 2 & 350 & 730 & 130 & 5.442 \\
8 & 2 & 350 & 1070 & 130 & 5.620 \\
9 & 1 & 350 & 900 & 80 & 7.622 \\
10 & 3 & 350 & 900 & 80 & 6.290 \\
11 & 1 & 350 & 900 & 130 & 13.270 \\
12 & 3 & 350 & 900 & 130 & 6.450 \\
13 & 2 & 320 & 730 & 105 & 4.750 \\
14 & 2 & 380 & 730 & 105 & 3.770 \\
15 & 2 & 320 & 1070 & 105 & 4.200 \\
16 & 2 & 380 & 1070 & 105 & 4.870 \\
17 & 1 & 350 & 730 & 105 & 6.049 \\
18 & 3 & 350 & 730 & 105 & 7.380 \\
19 & 1 & 350 & 1070 & 105 & 5.947 \\
20 & 3 & 350 & 1070 & 105 & 5.500 \\
21 & 2 & 320 & 900 & 80 & 5.890 \\
22 & 2 & 380 & 900 & 80 & 4.920 \\
23 & 2 & 320 & 900 & 130 & 6.080 \\
24 & 2 & 380 & 900 & 130 & 4.650 \\
25 & 2 & 350 & 900 & 105 & 5.500 \\
26 & 2 & 350 & 900 & 105 & 5.250 \\
27 & 2 & 350 & 900 & 105 & 5.600 \\
\hline
\end{tabular}

It can be observed from the Table 5 that the lowest reading of surface roughness (i.e., $\mathrm{Ra}=3.77 \mu \mathrm{m}$ ) was obtained in the specimen of Run Order \#14, having a wall thickness of $2.0 \mathrm{~mm}$, laser power of 380 watts, scan speed of $730 \mathrm{~mm} / \mathrm{s}$, and hatch distance of $105 \mu \mathrm{m}$. The highest value of SR (i.e., $13.27 \mu \mathrm{m}$ ) was recorded in the specimen with run order \#11. The corresponding values of wall thickness, laser power, scan speed, and hatch distance were $1.0 \mathrm{~mm}, 350$ watts, $900 \mathrm{~mm} / \mathrm{s}$, and $130 \mu \mathrm{m}$, respectively. The graphical representation based on experimental data is also described below in Figure 5. This graph depicts the relationship between the surface roughness and the values of the perspective parameter.

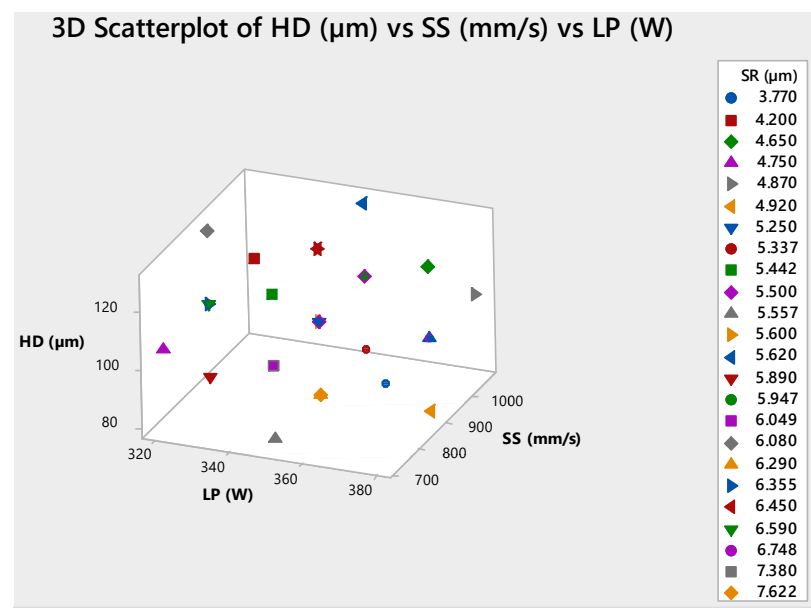

Figure 5. SR in respect to each of the parameters. 


\subsubsection{Dimensional Accuracy of the Samples}

To study the effect of process parameters on the dimensional quality of the samples was also one of the objectives of the experimentation. The dimensional measurements (i.e., length and height) were measured using a digital vernier caliper. The design values for length and height were $55 \mathrm{~mm}$ and $12 \mathrm{~mm}$, respectively, as given in Figure 2. The measurements of height were taken at five different points along the longitudinal axis, while length was recorded four times for every specimen. The average of these values was taken and are given in Table 6.

Table 6. Average values of the length and height of the samples.

\begin{tabular}{ccccccc}
\hline Run Ord. & WT (mm) & LP (W) & SS (mm/s) & HD $(\boldsymbol{\mu m})$ & Length $(\mathbf{m m})$ & $\begin{array}{c}\text { Height } \\
(\mathbf{m m})\end{array}$ \\
\hline 1 & 1 & 320 & 900 & 105 & 54.818 & 12.025 \\
2 & 3 & 320 & 900 & 105 & 54.920 & 12.030 \\
3 & 1 & 380 & 900 & 105 & 54.805 & 12.068 \\
4 & 3 & 380 & 900 & 105 & 54.933 & 12.050 \\
5 & 2 & 350 & 730 & 80 & 54.958 & 12.020 \\
6 & 2 & 350 & 1070 & 80 & 54.943 & 12.045 \\
7 & 2 & 350 & 730 & 130 & 54.953 & 12.018 \\
8 & 2 & 350 & 1070 & 130 & 54.920 & 12.055 \\
9 & 1 & 350 & 900 & 80 & 54.795 & 12.073 \\
10 & 3 & 350 & 900 & 80 & 54.940 & 12.060 \\
11 & 1 & 350 & 900 & 130 & 54.895 & 12.033 \\
12 & 3 & 350 & 900 & 130 & 54.965 & 12.070 \\
13 & 2 & 320 & 730 & 105 & 54.883 & 12.025 \\
14 & 2 & 380 & 730 & 105 & 54.905 & 12.055 \\
15 & 2 & 320 & 1070 & 105 & 54.900 & 12.025 \\
16 & 2 & 380 & 1070 & 105 & 54.920 & 12.035 \\
17 & 1 & 350 & 730 & 105 & 54.848 & 11.998 \\
18 & 3 & 350 & 730 & 105 & 54.950 & 12.010 \\
19 & 1 & 350 & 1070 & 105 & 54.883 & 12.008 \\
20 & 3 & 350 & 1070 & 105 & 54.888 & 12.020 \\
21 & 2 & 320 & 900 & 80 & 54.920 & 12.028 \\
22 & 2 & 380 & 900 & 80 & 54.935 & 12.060 \\
23 & 2 & 320 & 900 & 130 & 54.888 & 12.078 \\
24 & 2 & 380 & 900 & 130 & 54.918 & 12.073 \\
25 & 2 & 350 & 900 & 105 & 54.913 & 12.065 \\
26 & 2 & 350 & 900 & 105 & 54.983 & 12.043 \\
27 & 2 & 350 & 900 & 105 & 54.963 & 12.038 \\
\hline
\end{tabular}

It can be inferred from Table 6 that for the length of the specimens, the highest deviation from the design value occurred in run \#9, yielding an average height of $54.795 \mathrm{~mm}$ at a wall thickness of $1.0 \mathrm{~mm}$, laser power of 350 watts, scan speed of $900 \mathrm{~mm} / \mathrm{s}$, and hatch distance of $80 \mu \mathrm{m}$. The highest accuracy in the height was observed in run \#26 with a recorded value of the average height being $54.983 \mathrm{~mm}$. The corresponding values of wall thickness, laser power, scan speed and hatch distance were $2.0 \mathrm{~mm}, 350$ watts, $900 \mathrm{~mm} / \mathrm{s}$, and $105 \mu \mathrm{m}$, respectively. For height of the specimens, the least precise value (i.e., $12.078 \mathrm{~mm}$ ) was recorded in run \#23, having process parameters of wall thickness = $2.0 \mathrm{~mm}$, laser power $=320$ watts, scan speed $=900 \mathrm{~mm} / \mathrm{s}$, and hatch distance $=130 \mu \mathrm{m}$. The highest accurate value of $11.998 \mathrm{~mm}$ was noted in run \#17 with relevant values of wall thickness, laser power, scan speed, and hatch distance being $1.0 \mathrm{~mm}, 350$ watts, $730 \mathrm{~mm} / \mathrm{s}$, and $105 \mu \mathrm{m}$, respectively. The summary of the graphical representation based on experimental results is given below. The Figure 6 describes the relationship between length and height and perception parameter values. 

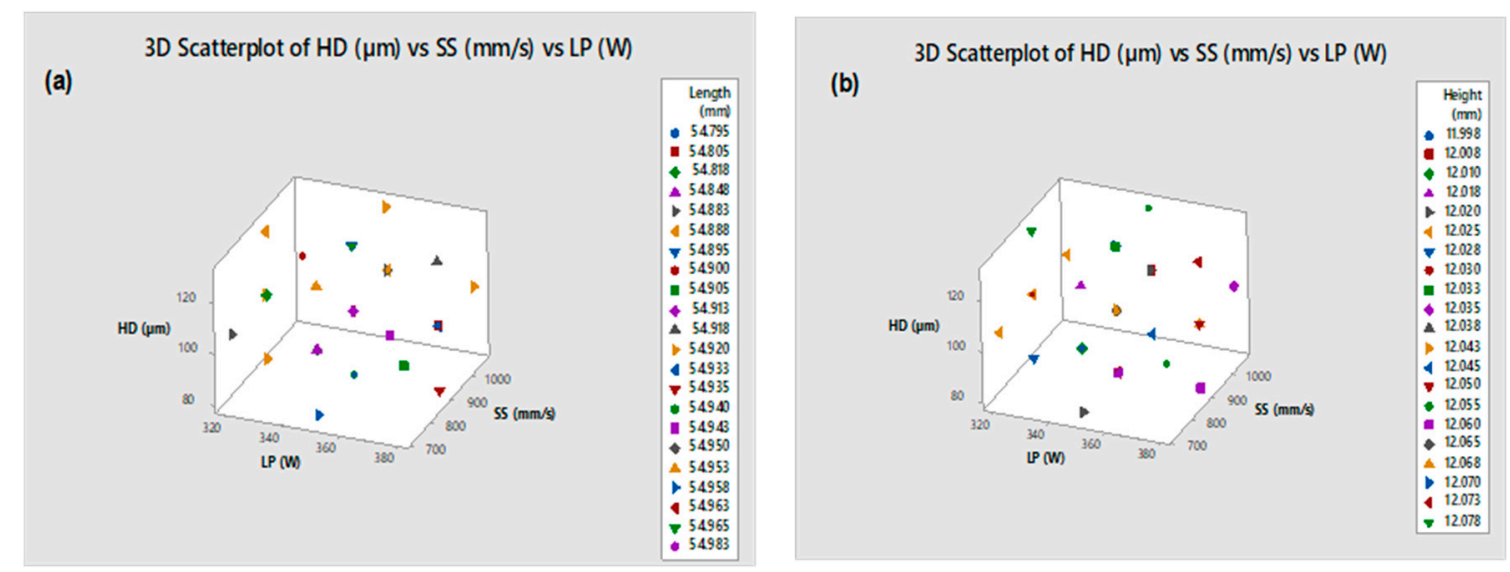

Figure 6. All plot parameter effects for (a) length and (b) height.

\subsection{Surface Roughness}

The main effects plot and interaction plot for SR are given in Figures 7 and 8, respectively.

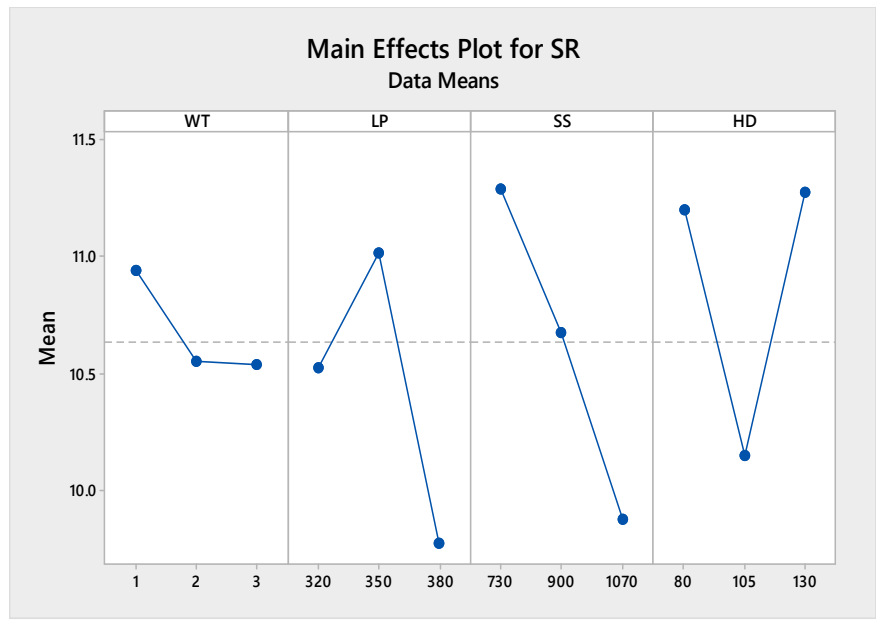

Figure 7. Main effects plot for SR.

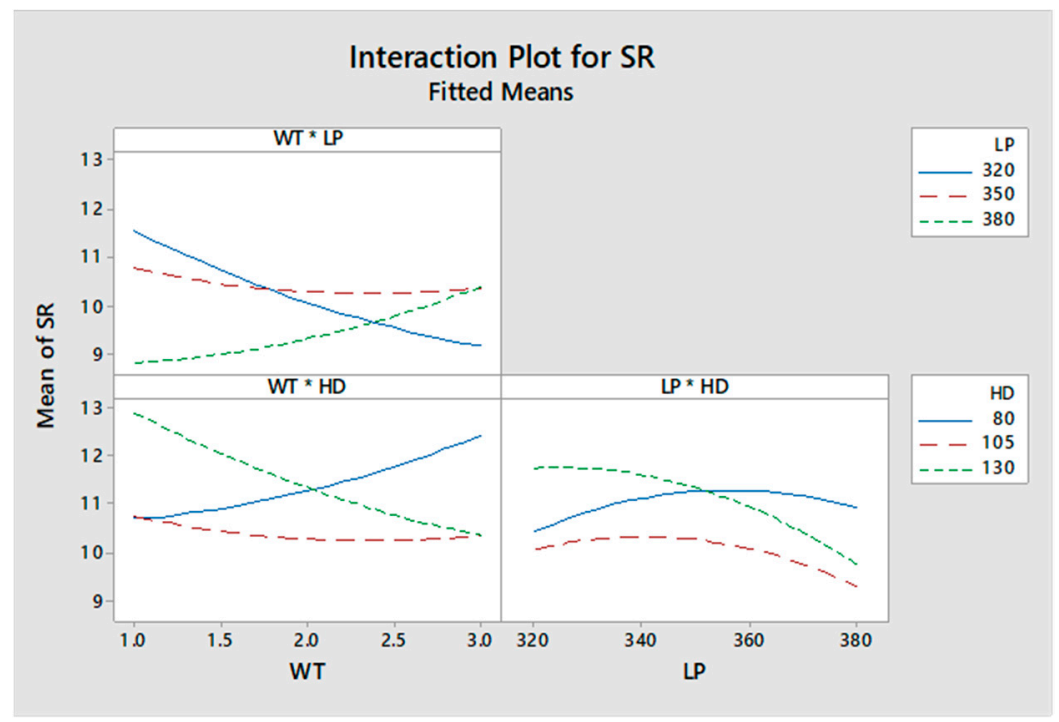

Figure 8. Interaction plot for SR. 
The main effect plot shows the mean of the response at every level of process parameter. Grand mean is displayed by drawing a horizontal line. The influence of process parameters is observed by the slope of the line which joins different levels of the process parameters. A steeper line indicates greater influence on response, while a line parallel to the grand mean displays a lesser effect on the response. It is clear from Figure 7 that scan speed had the greatest effect on surface roughness followed by laser power, while wall thickness had the least effect on the SR. The optimum value for surface roughness was attained at a scan speed of $900 \mathrm{~mm} / \mathrm{s}$, laser power of $380 \mathrm{~W}$, and hatch distance of $105 \mu \mathrm{m}$.

The interaction among process parameters can be visualized by an interaction plot (Figure 8). In the plot, parallel lines point to no interaction. The interaction was very significant when lines moved away from being parallel. The plot indicates that a low value of SR was achieved at a high value of laser power and medium value of hatch distance. Significant interaction existed between hatch distance and wall thickness. There was a greater influence for hatch distance values of $80 \mu \mathrm{m}$ and $130 \mu \mathrm{m}$ at all values of wall thickness. There was also a significant interaction between the laser power of $380 \mathrm{~W}$ and wall thickness greater than $2.0 \mathrm{~mm}$.

\section{Regression Equation}

The regression equation based on the chosen quadratic model is given below in Equation (1).

$$
\begin{aligned}
& S R=-92.5-4.40 W T+0.518 L P+0.0316 S S+0.124 H D+0.286 W T * W T \\
& -0.000654 L P * L P+0.000002 S S * S S+0.001657 H D * H D+0.0327 W T * L P- \\
& 0.00436 W T * S S-0.0427 W T * H D-0.000056 L P * S S-0.000832 L P * H D \\
& -0.000105 S S * H D
\end{aligned}
$$

\subsection{Dimensional Accuracy}

\subsubsection{Length of the Samples}

The main effects plot for length was drawn and is given below in Figure 9.

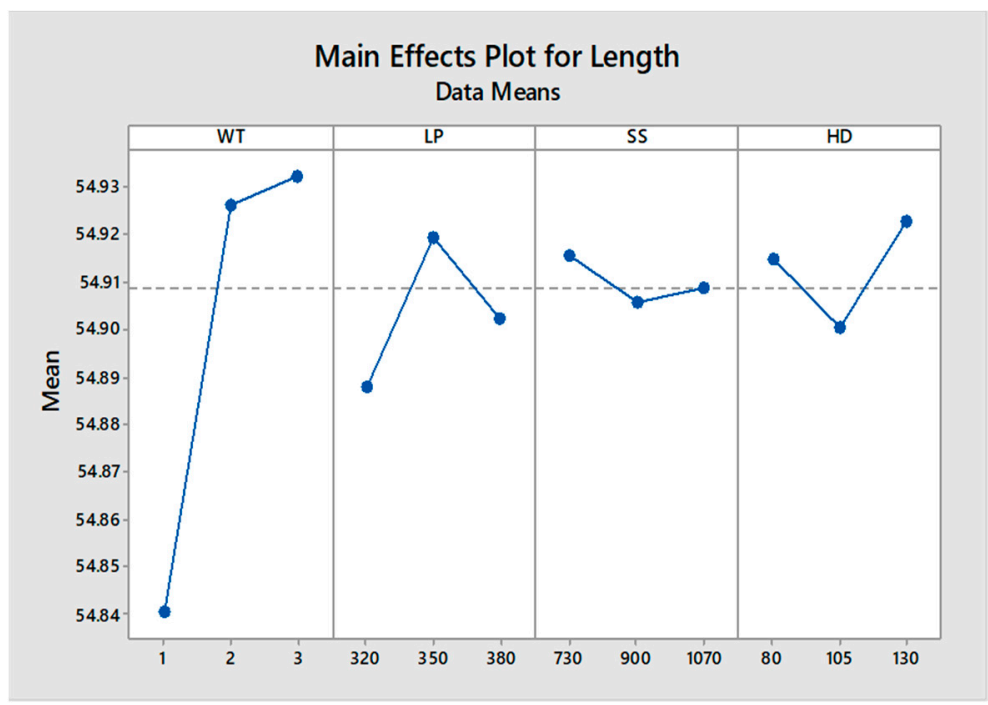

Figure 9. Main effects plot for length.

It is clear from the figure above that wall thickness had the greatest effect on the dimensional accuracy of the samples in terms of length, while scan speed had the least effect on length. The most precise value for length was attained at a wall thickness of 3.0 $\mathrm{mm}$, laser power of $350 \mathrm{~W}$, scan speed of $730 \mathrm{~mm} / \mathrm{s}$, and hatch distance of $130 \mu \mathrm{m}$. 
Regression Equation

The regression equation based on the chosen quadratic model is given below in Equation (2).

$$
\begin{aligned}
& \text { Length }=49.04+0.380 W T+0.0279 L P+0.00110 S S+0.00118 H D-0.0498 W T * W T \\
& -0.000041 L P * L P-0.000002 H D * H D+0.000208 W T * L P \\
& -0.000143 W T * S S-0.000750 W T * H D+0.000005 L P * H D \\
& -0.000001 S S * H D
\end{aligned}
$$

\subsubsection{Height of the Samples}

The main effects plot for the height was drawn and is given below in Figure 10. It is clear from the figure above that laser power and scan speed had the greatest effect on the dimensional accuracy of the samples in terms of height. The most precise value for height was attained at a wall thickness of $1.0 \mathrm{~mm}$, laser power of $320 \mathrm{~W}$, scan speed of $730 \mathrm{~mm} / \mathrm{s}$, and hatch distance of $105 \mu \mathrm{m}$.

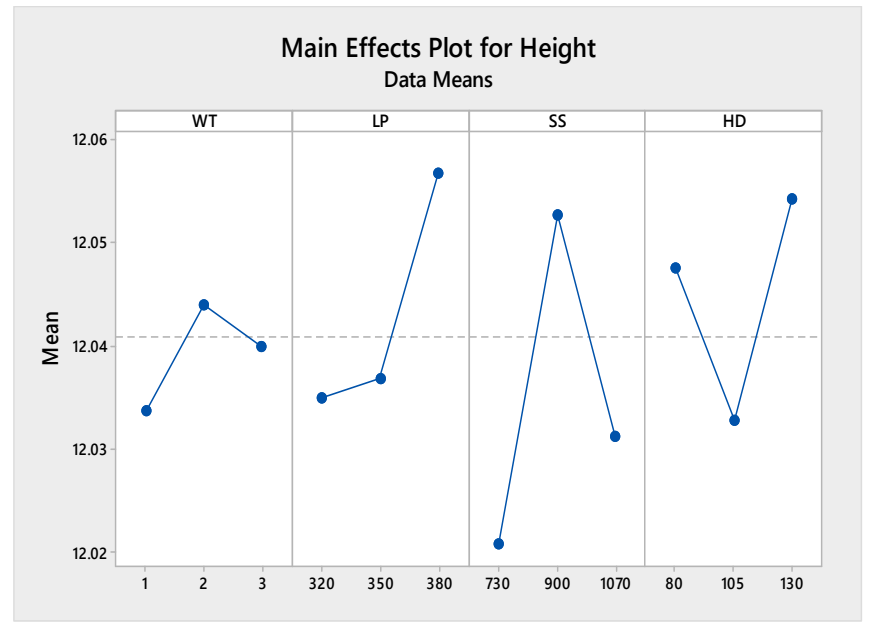

Figure 10. Main effects plot for height.

Regression Equation

The regression equation based on the chosen quadratic model is given below in Equation (3).

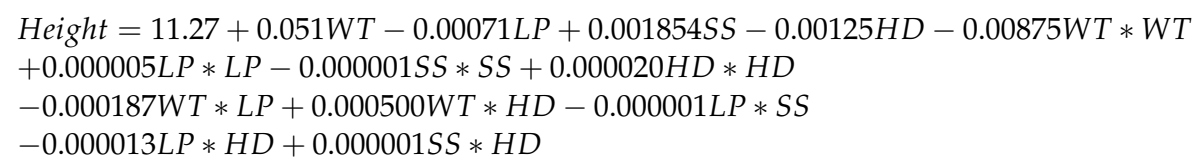

\subsection{Selection of Optimum Process Parameters}

Optimizing the process parameters for the responses was also one of the aims of the study. Minitab 17 was used to define the optimal process parameters to obtain better surface and dimensional qualities. The optimization plot and set of optimum SLM process parameters are given below in Figure 11.

The composite desirability is a single measure that combines the individual desirability of all the responses into a single measure. The figure below illustrates those responses were optimized and a composite desirability of 0.7472 was achieved. These optimized values of the response were obtained at a wall thickness of $2.7172 \mathrm{~mm}$, laser power of $320 \mathrm{~W}$, scan speed of $730 \mathrm{~mm} / \mathrm{s}$, and hatch distance of $94.1414 \mu \mathrm{m}$. Thus, these values combined make up a set of optimum process parameters against SR, length, and height as responses. 


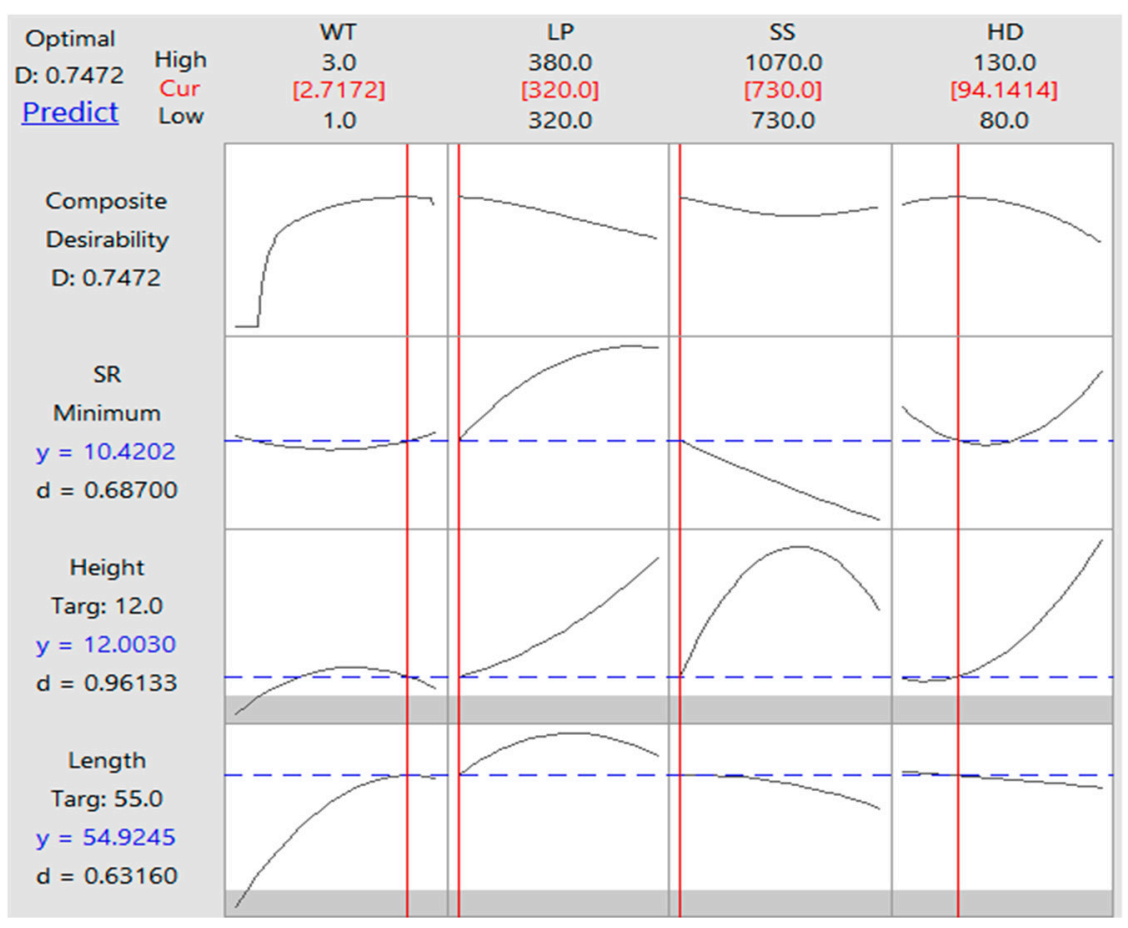

Figure 11. Optimization plot for SR, height, and length.

\section{Conclusions}

In this research work, the influence of SLM process parameters (i.e., wall thickness, laser power, scan speed, and hatch distance) on the surface and dimensional quality of AlSi10Mg specimens was studied. Response surface methodology was applied for DOE, analysis, prediction, and optimization purposes. ANOVA was applied to observe the effect of input factors on the responses. The conclusions made on the basis of the current study are listed below:

(1) With $p$-value and F-test value, wall thickness proved to have the most substantial influence on the length of the specimens in terms of dimensional accuracy. Length accuracy improved greatly when wall thickness varied from 1.0 to $2.0 \mathrm{~mm}$. A further improvement in accuracy was observed when wall thickness varied from 2.0 to $3.0 \mathrm{~mm}$;

(2) The response estimation model developed for length of the specimens was significant and yielded an R2 of $82.14 \%$. This means that the developed model fits more than $80 \%$ of the response data;

(3) The values for SR, length, and height were predicted on the basis of respective regression equations developed with regression analysis of the responses. The SR, length, and height were predicted accurately with minimum error of $0.005 \%, 0.0 \%$, and $0.002 \%$, respectively, as compared to experimental values;

(4) The most precise value for height was achieved at a wall thickness of $1.0 \mathrm{~mm}$, laser power of $320 \mathrm{~W}$, scan speed of $730 \mathrm{~mm} / \mathrm{s}$, and hatch distance of $105 \mu \mathrm{m}$;

(5) The most accurate value for length was attained at a wall thickness of $3.0 \mathrm{~mm}$, laser power of $350 \mathrm{~W}$, scan speed of $730 \mathrm{~mm} / \mathrm{s}$, and hatch distance of $130 \mu \mathrm{m}$;

(6) Multi-objective optimization methods can be used to optimize different process parameters of the SLM process simultaneously;

(7) More statistical methods, such as the Taguchi method, artificial neural networks, fuzzy logic, genetic algorithms, and grey relational analysis, can be applied to analyze results. 
Author Contributions: Conceptualization, D.H. and M.W.; methodology, H.E., S.R.; software, M.W.; validation, D.H., M.W. and P.G.; formal analysis, H.E.; investigation, M.W.; resources, H.E.; data curation, D.H.; writing_original draft preparation, M.W.; writing—review and editing, S.R.; visualization, M.E.; supervision, D.H.; project administration, P.G.; funding acquisition H.E. All authors have read and agreed to the published version of the manuscript.

Funding: This work was supported by the China National Key R\&D Program (2018YFD0400800 and 2018YFB1106303), the National Natural Science Foundation of China (51975006), and the PostGraduate Education Project of Beijing (11000101010).

Conflicts of Interest: The authors declare no conflict of interest.

$\begin{array}{ll}\text { Abbreviations } & \\ \text { Nomenclature } & \\ \text { ASTM } & \text { American Society for Testing and Materials } \\ \text { AM } & \text { Additive Manufacturing } \\ \text { SLM } & \text { Selective Laser Melting } \\ \text { EBM } & \text { Electron Beam Melting } \\ \text { DED } & \text { Directed Energy Deposition } \\ \text { BBD } & \text { Box-Behnken Design } \\ \text { RSM } & \text { Response Surface Methodology } \\ \text { SEM } & \text { Scanning Electron Microscope } \\ \text { 3D } & \text { Three Dimensional } \\ \text { CAD } & \text { Computer-Aided Design } \\ \text { DOE } & \text { Design of Experiment } \\ \text { CCD } & \text { Central Composite Design } \\ \text { BBD } & \text { Box-Behnken Design } \\ \text { EIMSE } & \text { Expected Integrated Mean Squared Error } \\ \text { SEM } & \text { Scanning Electron Microscope } \\ \text { SR } & \text { Surface Roughness } \\ \text { WT } & \text { Wall Thickness } \\ \text { Auto Fab } & \text { Auto Fabrication } \\ \text { LP } & \text { Laser Power } \\ \text { SS } & \text { Scan Speed } \\ \text { HD } & \text { Hatch Distance }\end{array}$

\section{References}

1. Kruth, J.-P.; Levy, G.; Klocke, F.; Childs, T. Consolidation phenomena in laser and powder-bed based layered manufacturing. CIRP Ann. 2007, 56, 730-759. [CrossRef]

2. Conner, B.P.; Manogharan, G.P.; Martof, A.N.; Rodomsky, L.M.; Rodomsky, C.M.; Jordan, D.C.; Limperos, J.W. Making sense of 3-D printing: Creating a map of additive manufacturing products and services. Addit. Manuf. 2014, 1, 64-76. [CrossRef]

3. Maamoun, A.H.; Elbestawi, M.; Dosbaeva, G.K.; Veldhuis, S.C. Thermal post-processing of AlSi10Mg parts produced by Selective Laser Melting using recycled powder. Addit. Manuf. 2018, 21, 234-247. [CrossRef]

4. Martin, J.H.; Yahata, B.D.; Hundley, J.M.; Mayer, J.A.; Schaedler, T.A.; Pollock, T.M. 3D printing of high-strength aluminum alloys. Nature 2017, 549, 365-369. [CrossRef]

5. Majeed, A.; Zhang, Y.F.; Lv, J.X.; Peng, T.; Waqar, S.; Atta, Z. Study the effect of heat treatment on the relative density of SLM built parts of AlSi10Mg alloy. In Proceedings of the 48th International Conference on Computers and Industrial Engineering (CIE 2018), Auckland, New Zealand, 2-5 December 2018.

6. Sing, S.L.; An, J.; Yeong, W.Y.; Wiria, F.E. Laser and electron-beam powder-bed additive manufacturing of metallic implants: A review on processes, materials and designs. J. Orthop. Res. 2016, 34, 369-385. [CrossRef]

7. Elahi, H.; Eugeni, M.; Gaudenzi, P. A review on mechanisms for piezoelectric-based energy harvesters. Energies 2018, 11, 1850. [CrossRef]

8. Elahi, H. The investigation on structural health monitoring of aerospace structures via piezoelectric aeroelastic energy harvesting. Microsyst. Technol. 2020, 1-9. [CrossRef]

9. Elahi, H.; Eugeni, M.; Fune, F.; Lampani, L.; Mastroddi, F.; Paolo Romano, G.; Gaudenzi, P. Performance evaluation of a piezoelectric energy harvester based on flag-flutter. Micromachines 2020, 11, 933. [CrossRef]

10. Gibson, I.; Rosen, D.W.; Stucker, B. Design for Additive Manufacturing. In Additive Manufacturing Technologies; Springer Science and Business Media LLC: Berlin/Heidelberg, Germany, 2010; pp. 299-332. 
11. Abbas, I.; Wang, Y.; Elahi, H.; Siddiqui, M.A.; Ullah, M.; Qayyum, F. Effect of MoSi2-Si3N4/SiC Multi-Layer Coating on the Oxidation Resistance of Carbon/Carbon Composites above 1770 K. J. Compos. Sci. 2020, 4, 86. [CrossRef]

12. Elahi, H.; Munir, K.; Eugeni, M.; Atek, S.; Gaudenzi, P. Energy Harvesting towards Self-Powered IoT Devices. Energies 2020, 13, 5528. [CrossRef]

13. Dadbakhsh, S.; Hao, L.; Jerrard, P.G.E.; Zhang, D.Z. Experimental investigation on selective laser melting behavior and processing windows of in situ reacted $\mathrm{Al} / \mathrm{Fe}_{2} \mathrm{O}_{3}$ powder mixture. Powder Technol. 2012, 231, 112-121. [CrossRef]

14. Calignano, F.; Manfredi, D.; Ambrosio, E.P.; Iuliano, L.; Fino, P. Influence of process parameters on surface roughness of aluminum parts produced by DMLS. Int. J. Adv. Manuf. Technol. 2013, 67, 2743-2751. [CrossRef]

15. Leary, M. Surface roughness optimization for selective laser melting (SLM): Accommodating relevant and irrelevant surfaces. In Laser Additive Manufacturing; Elsevier: Amsterdam, The Netherlands, 2017; pp. 99-118.

16. Mohammadi, M.; Asgari, H. Achieving low surface roughness AlSi10Mg_200C parts using direct metal laser sintering. Addit. Manuf. 2018, 20, 23-32. [CrossRef]

17. Wang, L.-Z.; Wang, S.; Wu, J.-J. Experimental investigation on densification behavior and surface roughness of AlSi10Mg powders produced by selective laser melting. Opt. Laser Technol. 2017, 96, 88-96. [CrossRef]

18. Tian, Y.; Tomus, D.; Rometsch, P.; Wu, X. Influences of processing parameters on surface roughness of Hastelloy X produced by selective laser melting. Addit. Manuf. 2017, 13, 103-112. [CrossRef]

19. Rakesh, C.S.; Priyanka, N.; Jayaganthan, R.; Vasa, N.J. Effect of build atmosphere on the mechanical properties of AlSi10Mg produced by selective laser melting. Mater. Today Proc. 2018, 5, 17231-17238. [CrossRef]

20. Han, X.; Zhu, H.; Nie, X.; Wang, G.; Zeng, X. Investigation on Selective Laser Melting AlSi10Mg Cellular Lattice Strut: Molten Pool Morphology, Surface Roughness and Dimensional Accuracy. Materials 2018, 11, 392. [CrossRef] [PubMed]

21. Majeed, A.; Lv, J.; Peng, T. A framework for big data driven process analysis and optimization for additive manufacturing. Rapid Prototyp. J. 2019, 25, 308-321. [CrossRef]

22. Maamoun, A.H.; Xue, Y.F.; Elbestawi, M.A.; Veldhuis, S.C. The effect of selective laser melting process parameters on the microstructure and mechanical properties of Al6061 and AlSi10Mg alloys. Materials 2019, 12, 12. [CrossRef]

23. Sing, S.L.; Wiria, F.E.; Yeong, W.Y. Selective laser melting of lattice structures: A statistical approach to manufacturability and mechanical behavior. Robot. Comput. Manuf. 2018, 49, 170-180. [CrossRef]

24. Ghani, S.A.C.; Zakaria, M.H.; Harun, W.S.W.; Zaulkafilai, Z. Dimensional accuracy of internal cooling channel made by selective laser melting (SLM) And direct metal laser sintering (DMLS) processes in fabrication of internally cooled cutting tools. In MATEC Web of Conferences; EDP Sciences: Les Ulis, France, 2017.

25. Fateri, M.; Gebhardt, A.; Thuemmler, S.; Thurn, L. Experimental Investigation on Selective Laser Melting of Glass. Phys. Procedia 2014, 56, 357-364. [CrossRef]

26. Wang, R.-J.; Wang, L.; Zhao, L.; Liu, Z. Influence of process parameters on part shrinkage in SLS. Int. J. Adv. Manuf. Technol. 2006, 33, 498-504. [CrossRef]

27. Aboulkhair, N.T. Additive Manufacture of an Aluminum Alloy: Processing, Microstructure, and Mechanical Properties; University of Nottingham: Nottingham, UK, 2016.

28. Böckin, D.; Tillman, A.-M. Environmental assessment of additive manufacturing in the automotive industry. J. Clean. Prod. 2019, 226, 977-987. [CrossRef]

29. Allen, T.T. Introduction to Engineering Statistics and Lean Six Sigma: Statistical Quality Control and Design of Experiments and Systems; Springer: Berlin/Heidelberg, Germany, 2018.

30. Allen, T.T. Introduction to Engineering Statistics and Six Sigmas': Statistical Quality Control and Design of Experiments and Systems; Springer Science \& Business Media: Berlin/Heidelberg, Germany, 2016.

31. Kruth, J.P.; Badrossamay, M.; Yasa, E.; Deckers, J.; Thijs, L.; Van Humbeeck, J. Part and material properties in selective laser melting of metals. In Proceedings of the 16th International Symposium on Electro machining (ISEM XVI), Shanghai, China, 19-23 April 2010.

32. Alrbaey, K.; Wimpenny, D.; Tosi, R.; Manning, W.; Moroz, A. On Optimization of Surface Roughness of Selective Laser Melted Stainless Steel Parts: A Statistical Study. J. Mater. Eng. Perform. 2014, 23, 2139-2148. [CrossRef]

33. Alsoufi, M.S.; Elsayed, A.E. Surface Roughness Quality and Dimensional Accuracy-A Comprehensive Analysis of $100 \%$ Infill Printed Parts Fabricated by a Personal/Desktop Cost-Effective FDM 3D Printer. Mater. Sci. Appl. 2018, 9, 11-40. [CrossRef]

34. Calignano, F.; Lorusso, M.; Pakkanen, J.; Trevisan, F.; Ambrosio, E.P.; Manfredi, D.; Fino, P. Investigation of accuracy and dimensional limits of part produced in aluminum alloy by selective laser melting. Int. J. Adv. Manuf. Technol. 2016, 88, 451-458. [CrossRef]

35. Majeed, A.; Zhang, Y.; Lv, J.; Peng, T.; Atta, Z.; Ahmed, A. Investigation of T4 and T6 heat treatment influences on relative density and porosity of AlSi10Mg alloy components manufactured by SLM. Comput. Ind. Eng. 2020, 139, 106194. [CrossRef] 